\title{
Genomic Characterization of a Brazilian TT Virus Isolate Closely Related to SEN Virus-F
}

\author{
Leonardo Diniz-Mendes, Sylvie Devalle, Christian Niel ${ }^{+}$
}

Departamento de Virologia, Instituto Oswaldo Cruz-Fiocruz, Av. Brasil 4365, 21045-900 Rio de Janeiro, RJ, Brasil

SEN virus (SENV) is a circular, single stranded DNA virus that has been first characterized in the serum of a human immunodeficiency virus type 1 (HIV-1)-infected patient. Eight genotypes of SENV (A-H) have been identified and further recognized as variants of TT virus (TTV) in the family Circoviridae. Here we describe the first genomic characterization of a SENV isolate (5-A) from South America. Using 'universal' primers, able to amplify most, if not all, TTV/SENV genotypes, a segment of > $3 \mathrm{~kb}$ was amplified by polymerase chain reaction from the serum of an HIV-1 infected patient. The amplicon was cloned and a 3087-nucleotide sequence was determined, that showed a high (85\%) homology with the sequence of the Italian isolate SENV-F. Proteins encoded by open reading frames (ORFs) 1 to 4 consisted of 758, 129, 276, and 267 amino acids, respectively. By phylogenetic analysis, isolate 5-A was classified into TTV genotype 19 (phylogenetic group 3), together with SENV-F and TTV isolate SAa-38.

Key words: hepatitis - human immunodeficiency virus type 1 - nucleotide sequencing - open reading frames 1-4 -

SEN virus-F - TT virus

Recently, a new circular, single stranded DNA virus, related to the TT virus (TTV) prototype in the genus Anellovirus (Circoviridae family), was identified and designated as SEN virus (SENV) after the initials of the infected patient, a human immunodeficiency virus (HIV) infected injection drug user (Fiordalisi et al. 2000). Phylogenetic analysis of SENV isolates has demonstrated the existence of eight genotypes (A-H), all of which showing $<55 \%$ sequence homology at the nucleotide level and < $37 \%$ at the amino acid (aa) level with TTV prototype TA278 (Tanaka et al. 2001). However, TTV and SENV show a similar genomic organization. Analysis of the complete TTV nucleotide sequence $(3.8 \mathrm{~kb})$ has identified two major, partially overlapping open reading frames (ORFs), ORF1 and ORF2, which encode 770 and 120 aas, respectively (Okamoto et al. 1998). An alternative RNA splicing mechanism generates two additional coding regions, ORF3 (286 codons) and ORF4 (289 codons). The N-terminal portions of ORF3 and ORF4 products are common to ORF2 product, while the C-terminal moieties of ORF1, ORF3, and ORF4 products are encoded by the same genome region, each in a different reading frame, without homology to each other (Kamahora et al. 2000, Okamoto et al. 2000).

Human circoviruses are ubiquitous and most humans are infected with at least one (and frequently more than one) genotype. These viruses show a very wide range of sequence divergence, and the number of recognized genotypes has increased continuously in the recent years. A comprehensive classification of the TTV-related viruses

Financial support: CNPq and Faperj

${ }^{+}$Corresponding author. Fax: + 55-21-22706397.

E-mail:niel@ioc.fiocruz.br

Received 6 November 2003

Accepted 1 March 2004 into five major phylogenetic groups (1-5) has been proposed (Peng et al. 2002), in which the eight SENV genotypes were included in group 3 .

Accumulated evidence suggests that many cases of viral hepatitis are not related to the well-characterized hepatitis viruses A to E (Mushahwar 2000). In this context, TTV was originally recovered from a patient with posttransfusion hepatitis of unknown etiology (Nishizawa et al. 1997). Moreover, a strong association has been found between acute infection with SENV-D or SENV-H and the development of transfusion associated non-A to E hepatitis (Unemura et al. 2001). On the other hand, TTV group 4 has been recently associated with acute respiratory diseases in children (Maggi et al. 2003). However, whether TTV and SENV are causative agents of any disease has not been clearly demonstrated.

In the last two years, several studies, performed in Europe, Asia, and North America, have evaluated the prevalence, modes of transmission and clinical relevance of SENV (Shibata et al. 2001, Unemura et al. 2001, Kao et al. 2002, Mikuni et al. 2002, Pirovano et al. 2002a,b, Yoshida et al. 2002, Schröter et al. 2002, 2003). However, few data are available regarding the circulation of SENV strains in South America. The present study constitutes the first genomic characterization of a SENV isolate from South America.

\section{MATERIALS AND METHODS}

Twenty-four serum samples, collected from 25-35 years old, HIV-1 infected patients (18 male and 6 female) living in Rio de Janeiro, Brazil, were used in this study. Twelve of the 18 men were homosexual or bisexual and four others reported having multiple sexual partners. All six women had a HIV-1 seropositive sexual partner. One TTV clone was sequenced in this study. It was derived from a 31year-old bisexual man, who was in stage IV of acquired immunodeficiency syndrome (AIDS) the most advanced stage according to the classification of the US Centers for Disease Control and Prevention. 
Viral DNA was extracted using phenol/chloroform after treatment of $250 \mu \mathrm{l}$ of serum with $0.5 \mathrm{mg} / \mathrm{ml}$ of proteinase $\mathrm{K}$ in the presence of $0.2 \mathrm{M} \mathrm{NaCl}, 0.25 \% \mathrm{SDS}$, for $4 \mathrm{~h}$ at $37^{\circ} \mathrm{C}$. After precipitation with ethanol, the pellet was dried and resuspended in $30 \mu \mathrm{l}$ of distilled water.

Polymerase chain reaction (PCR) assays were performed using $2.5 \mu \mathrm{l}$ of DNA and 0.75 unit of a mixture of Taq and Pyrococcus species GB-D thermostable DNA polymerases (Elongase, Invitrogen, Carlsbad, CA) in a final volume of $25 \mu \mathrm{l}$. Oligonucleotide primers used in this study were T1S (external sense), T1A (external antisense), T2S (internal sense), and T2A (internal antisense), which have been designed at the 3' (primers sense) and 5' (primers antisense) ends of the conserved untranslated region, so that a large DNA segment (of approximately 3100 bp) was amplified, encompassing the most variable part (and all the ORFs) of the genome (Devalle \& Niel 2004). After an initial DNA denaturation for $30 \mathrm{~s}$ at $94^{\circ} \mathrm{C}$, first round amplification was performed for 35 cycles at $94^{\circ} \mathrm{C}$ for $20 \mathrm{~s}$, $59^{\circ} \mathrm{C}$ for $30 \mathrm{~s}$, and $68^{\circ} \mathrm{C}$ for $3 \mathrm{~min} 30 \mathrm{~s}$, followed by a final elongation of $10 \mathrm{~min}$ at $68^{\circ} \mathrm{C}$. One microliter of amplification product was used in a second round PCR which was done in the same conditions, only decreasing annealing temperature to $53^{\circ} \mathrm{C}$. PCR products $(10 \mu \mathrm{l})$ were loaded on a $2 \%$ agarose gel, electrophoresed, and stained with ethidium bromide to visualize DNA bands.

PCR products were cloned into the pCR2.1-TOPO vector (TOPO TA cloning kit, Invitrogen, San Diego, CA) according to the manufacturer's instructions. Recombinant plasmids were purified and the presence of inserts was confirmed after digestion with EcoRI restriction endonuclease, $2 \%$ agarose electrophoresis, and visualization of DNA bands under ultraviolet light. Nucleotide sequencing of one clone (5-A) was performed using the Big Dye Terminator cycle-sequencing kit (Applied Biosystems, Foster City, CA). Cycle sequencing was carried out with an automatic DNA sequencer (ABI model 373; Applied Biosystems) and performed in both orientations for confirmation. The nucleotide sequence is available in the DDBJ/EMBL/GenBank databases under the accession number AY449524.

The nucleotide sequence of clone 5-A was compared with previously characterized sequences using BLAST search (internet address http://www.ncbi.nlm.nih.gov/ BLAST/) to identify the samples most closely related to clone 5-A. The positions of the translation initiation codons, splice donor and acceptor sites, stop codons and polyadenylation site were determined by multiple sequence alignment performed with PILEUP program (Wisconsin Sequence Analysis Package, GCG, Madison, WI). This program, which uses the unweighted pair-group method with arithmetic averages (UPGMA) procedure, was also used for the construction of a phylogenetic tree.

\section{RESULTS}

Viral DNAs were extracted from 24 serum samples collected from HIV-1 infected patients, and submitted to nested PCR amplification using oligonucleotide primers T1S, T2S, T1A, and T2A. These primers have been designed in conserved genome regions to be able to amplify most, if not all, TTV/SENV DNAs and to generate a amplicon covering approximately $80 \%$ (and the whole coding region) of the viral genome (Devalle \& Niel 2004). Twenty-one ( $87 \%$ ) of the 24 samples tested were successfully amplified, and a DNA band of approximately $3.1 \mathrm{~kb}$ was observed after agarose gel electrophoresis. One of the amplicons was cloned and the entire nucleotide sequence of one clone (5-A) was determined.

The sequence was 3087 bp in length (nucleotides 2233309 , numbering according to TTV prototype TA278). Fig. 1 shows the localization of the four ORFs of isolate 5-A. ORF1 extended from nt 591 to nt 2864, and encoded a protein of 758 aas that showed an arginine-rich domain at its amino terminus (49\% Arg among residues 1-91). The translation initiation codon common to ORF2, ORF3, and ORF4 was located at nt 343 and the ORF2 stop codon at nt 730. ORF2 encoded therefore a putative protein of 129 aas. The donor site for alternative splice, the acceptor site for ORF3 and the acceptor site for ORF4 were situated at nt 728, 2391, and 2623, respectively, giving rise to an ORF3 of 276 aas and an ORF4 of 267 aas. The ORF4 stop codon (nts 3038-3040) and the unique polyadenylation signal (nts 3039-3044) were found to overlap in the motif TAATAAA.

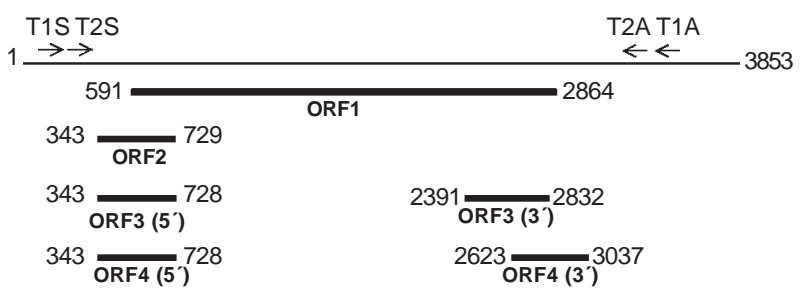

Fig. 1: localization of the four open reading frames (1-4) on the genome of isolate 5-A. For convenience, the circular genome of the virus is represented as a linear DNA. Since the total genomic length of the 5-A isolate has not been determined, numbering was based on TTV prototype isolate TA278 (3853 nt), assuming that the genome segment of isolate 5-A located upstream oligonucleotide T2S does not show any insertion or deletion. Note that the ORF2 stop codon was located one nucleotide downstream from the donor site for alternative splicing which generates ORF3 and ORF4.

Table I shows the percent identities (at nt and aa levels) between clone 5-A and TTV-related viruses belonging to the five major phylogenetic groups and whose ORFs 1 to 4 have been characterized. Clone 5-A showed a low (53.3-59.5\%) sequence homology with the five isolates. Despite the great nucleotide sequence divergence existing among the five groups, the sizes of the proteins appeared to be well conserved, with ORF1 product varying from 719 to 770 aas, ORF2 product from 115 to 130 aas, ORF3 protein from 260 to 303 aas, and ORF4 protein from 249 to 297 aas. When other TTV-related viruses were assessed (Table II), isolate 5-A showed a relatively high sequence homology with members of phylogenetic group 3, particularly with SENV-F and SAa-38 (82-85\% homology) and, in a lesser extent, with SENV-D and TJN01 (76$77 \%$ ).

A phylogenetic analysis was performed with the nucleotide sequences of clone 5-A and of 14 TTV/SENVs avail- 
TABLE I

Nucleotide and amino acid sequence identity between isolate 5-A and TTV-related viruses representative of the five major phylogenetic groups

\begin{tabular}{|c|c|c|c|c|c|c|c|c|c|c|c|}
\hline \multirow{2}{*}{ Isolate } & \multirow{2}{*}{$\begin{array}{l}\text { Genomic } \\
\text { group }\end{array}$} & \multirow{2}{*}{$\begin{array}{c}\text { Accession } \\
\text { number }\end{array}$} & \multirow{2}{*}{$\begin{array}{l}\text { Percent identity } \\
\text { (nucleotides) }\end{array}$} & \multicolumn{4}{|c|}{ Percent identity (amino acids) } & \multicolumn{4}{|c|}{ Number of amino acid residues } \\
\hline & & & & ORF1 & ORF2 & ORF3 & ORF4 & ORF1 & ORF2 & ORF3 & ORF \\
\hline $5-\mathrm{A}$ & & AY449524 & 100 & 100 & 100 & 100 & 100 & 758 & 129 & 276 & 267 \\
\hline TA278 & 1 & AB017610 & 56.1 & 47.3 & 50.4 & 46.9 & 50.6 & 770 & 120 & 286 & 289 \\
\hline KAV & 2 & AF435014 & 57.0 & 53.2 & 51.3 & 49.8 & 50.0 & 719 & 125 & 264 & 273 \\
\hline TYM9 & 3 & AB050448 & 59.5 & 45.0 & 50.4 & 48.8 & 45.9 & 748 & 115 & 260 & 249 \\
\hline КC009 & 4 & AB038621 & 53.3 & 45.7 & 47.6 & 44.4 & 47.1 & 733 & 128 & 303 & 297 \\
\hline CT39F & 5 & AB064604 & 56.3 & 47.5 & 54.1 & 42.7 & 47.8 & 743 & 130 & 272 & 266 \\
\hline
\end{tabular}

TABLE II

Nucleotide sequence identity (near full-length genome) between isolate 5-A and TTV/SENV isolates from different origins

\begin{tabular}{|c|c|c|c|c|}
\hline Isolate & Accession number & Genomic group & Genotype & Percent identity $^{a}$ \\
\hline JA1 & AF122916 & 1 & 2 & 55.1 \\
\hline Т3РB & AF247138 & 1 & 3 & 55.2 \\
\hline PMV & AF261761 & 2 & 17 & 56.1 \\
\hline Kt-08F & AB054647 & 2 & 22 & 56.1 \\
\hline $\mathrm{Kt}-10 \mathrm{~F}$ & AB054648 & 2 & 23 & 56.0 \\
\hline SAa-01 & AB060597 & 3 & 27 & 59.3 \\
\hline SAa-10 & AB060594 & 3 & 24 & 58.2 \\
\hline SAa-38 & AB060593 & 3 & 19 & 82.4 \\
\hline SAa-39 & AB060592 & 3 & 18 & 59.5 \\
\hline SAf-09 & AB060596 & 3 & 26 & 58.9 \\
\hline SAj-30 & AB060595 & 3 & 25 & 59.7 \\
\hline SANBAN & AB025946 & 3 & 13 & 60.1 \\
\hline SENV-A & AX025667 & 3 & 9 & 69.2 \\
\hline SENV-B & AX025677 & 3 & 10 & 63.0 \\
\hline SENV-C & AX025718 & 3 & 15 & 63.3 \\
\hline SENV-D & AX025730 & 3 & 12 & 76.5 \\
\hline SENV-E & AX025761 & 3 & 14 & 61.1 \\
\hline SENV-F & AX025822 & 3 & 19 & 84.7 \\
\hline SENV-G & AX025830 & 3 & 20 & 64.5 \\
\hline SENV-H & AX025838 & 3 & 16 & 63.1 \\
\hline TJN01 & AB028668 & 3 & 12 & 77.1 \\
\hline TJN02 & АВ028669 & 3 & 13 & 60.2 \\
\hline TUPB & AF247137 & 3 & 11 & 66.4 \\
\hline TUS01 & AB017613 & 3 & 11 & 67.1 \\
\hline TYM9 & AB050448 & 3 & 18 & 59.5 \\
\hline CT23F & AB064595 & 4 & N.A. & 52.7 \\
\hline CT25F & AB064596 & 4 & N.A. & 54.9 \\
\hline JT14F & AB064601 & 4 & N.A. & 53.1 \\
\hline CT44F & AB064605 & 5 & N.A. & 55.9 \\
\hline JT33F & AB064606 & 5 & N.A. & 56.1 \\
\hline JT34F & AB064607 & 5 & N.A. & 55.4 \\
\hline
\end{tabular}

$a$ : values above 80 are in bold and underlined; N.A.: not available (since no specific number was given to the genotypes represented by these isolates)

able in the DNA databanks, i.e. one from each of the phylogenetic groups $1,2,4$, and 5 , as well as 10 representative isolates from group 3, including the eight SENV genotypes. Phylogenetic tree (Fig. 2) shows that clone 5-A was classifiable into genotype 19 (phylogenetic group 3), together with isolates SENV-F and SAa-38. The sequences of the four putative proteins of SENV-F, SAa-38, and clone 5-A were aligned (Fig. 3). The most conserved region was the C-terminal portion of ORF3 product, a post-trans- lationally phosphorylated serine-rich region that has been suggested to modulate function of host cellular proteins and to play a role in maintaining persistent infection (Asabe et al. 2001). SENV-F ORF4 product appeared to be truncated when compared to the corresponding products of SAa-38 and clone 5-A. Of note, the tail of ORF4 of clone 5-A (positions 229 to 267) showed a high (82\%) homology with the corresponding ORF4 region of isolate SAa-38. 


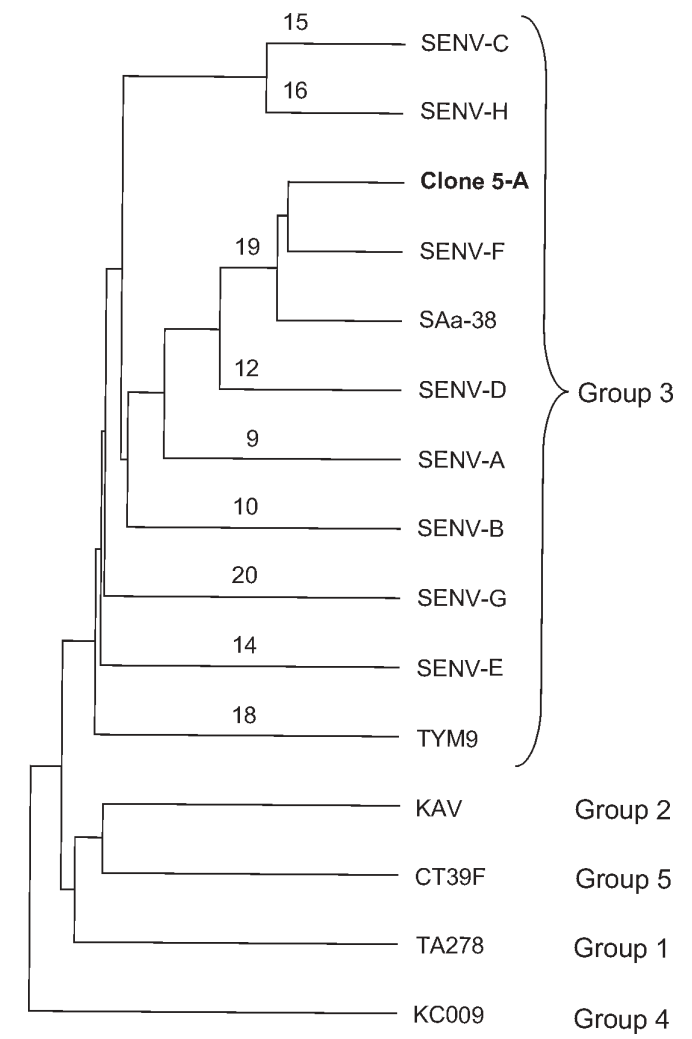

Fig. 2: phylogenetic tree inferred by using the UPGMA method from isolate 5-A and 14 reference sequences obtained from the GenBank database (accession numbers are indicated in Tables I and II). "Groups" refer to the five major TTV phylogenetic groups (1$5)$. Nrs on the branches refer to genotypes within phylogenetic group 3.

\section{DISCUSSION}

Evidence has accumulated that TTV viremia is extremely common in the general population worldwide (Prescott \& Simmonds 1998, Takahashi et al. 1998, Niel et al. 1999). TTV DNA has been detected at higher viral loads in HIV infected patients than in controls. It has thus been proposed that TTV load may reflect the degree of immune status of immunocompromised hosts (Christensen et al. 2000, Shibayama et al. 2001, Touinssi et al. 2001). Furthermore, coinfection of single individuals with different TTV isolates has been found more frequently in HIV infected patients than in blood donors (Sherman et al. 2001, Devalle $\&$ Niel 2004). In this study, a large (3.1 kb) segment of the SENV genome was PCR amplified. Since effective amplification of long targets are sometimes difficult, a mixture of thermostable DNA polymerases was used to increase PCR efficiency, making possible the successful amplification of TTV/SENV genomes from 21/24 (87\%) sera collected from HIV-1 infected patients. In a parallel experiment, however, no amplification was obtained from 24 sera collected from blood donors (not shown). As the PCR assay used here was designed to amplify most, if not all, TTV/SENV genomes, it can be concluded that such a discrepancy between HIV infected patients and blood donors was likely due to a higher viral load (rather than a higher prevalence) in HIV infected patients.

The detection of SENV in Brazilian patients with chronic hepatitis of unknown etiology has been mentioned previously (Chemin et al. 2002), but without any details. The present study constitutes the first characterization of a SENV isolate from South America. The first SENV isolate identified in the world, namely SENV-A, was initially found in an Italian HIV infected patient (Tanaka et al. 2001). A high prevalence of genotype SENV-A has been later demonstrated in intravenous drug user HIV infected patients (Pirovano et al. 2002b). The virus characterized here was also found in an HIV infected patient, more precisely a bisexual, 31 year-old man who was at an advanced stage of AIDS. The virus showed a high (84.7\%) homology with SENV-F and was classified into genotype 19, together with isolates SENV-F and SAa-38. Further studies will be necessary to determine whether the other SENV genotypes (A-E, G, H) circulate or not in South America, both in HIV infected individuals and in the general population.

All eight SENV genotypes have been recently classified into TTV phylogenetic group 3, which is the group showing the major genetic diversity and including the largest number of genotypes (Okamoto \& Mayumi 2001, Peng et al. 2002). Here we observed a low (59-70\%) sequence homology between isolate 5-A, a variant not very distant of SENV-F, and well-characterized viral strains from group 3, as SANBAN (Hijikata et al. 1999), TUS01 (Okamoto et al. 1999), and TYM9 (Okamoto et al. 2000). At this respect, it should be kept in mind that the present classification of TTVs/SENVs in five phylogenetic groups is provisional and may be modified in the future if new genotypes, whose existence has been recently suggested (Kojima et al. 2003, Maggi et al. 2003, Devalle \& Niel 2004), are actually identified.

The natural history and pathogenic potential of TTVs/ SENVs are currently the subject of active investigation. These viruses have been proposed to be associated with hepatitis and acute respiratory diseases, although a causative effect has not been established. A possibility exists that certain strains cause disease while most others are non-pathogenic. In this context, studies like the present one, which contribute to determine which genotypes circulate in defined geographic regions, should be of great relevance in the future, when the clinical significance of the various TTV/SENV genotypes is known.

\section{REFERENCES}

Asabe SI, Nishizawa T, Iwanari H, Okamoto H 2001. Phosphorylation of serine-rich protein encoded by open reading frame 3 of the TT virus genome. Biochem Biophys Res Commun 286: 298-304.

Chemin I, Parana R, Trepo C 2002. A new viral agent, SEN virus (SENV), has been detected in patients from several countries: the pathogenic role of SENV in coinfections with hepatitis B virus or hepatitis C virus should be investigated. J Infect Dis 185: 710.

Christensen JK, Eugen-Olsen J, Sorensen M, Ullum H, Gjedde SB, Pedersen BK, Nielsen JO, Krogsgaard K 2000. Prevalence and prognostic significance of infection with TT virus in patients infected with human immunodeficiency virus. $J$ Infect Dis 181: 1796-1799. 
ORF1

SENV-F

$\mathrm{SAa}-38$

$5-\mathrm{A}$

SENV-F

$\mathrm{SAa}-38$

5-A

SENV-F

SAa -38

$5-\mathrm{A}$

SENV-F

$\mathrm{SAa}-38$

5-A

SENV-F

SAa -38

5-A

SENV-F

SAa -38

5-A

SENV-F

SAa -38

5-A

SENV-F

SAa-38

5-A

SENV-F

SAa -38

5-A

SENV-F SAa -38

5-A

\section{ORF2}

SENV-F SAa -38 5-A

SENV-F SAa-38 5-A

\section{ORF3 (C-terminus)}

SENV-F

$\mathrm{SAa}-38$

5-A

SENV-F

$\mathrm{SAa}-38$

$5-\mathrm{A}$

\section{ORF4 (C-terminus)}

SENV-F HRTRKPKRT SRRRLAFGDALAHLVPRKRSRSPRKSATTAAAQKTTQTATAVASPLAAPLPPT PKNKSPFTFKPTIFPPRE

SAa-38 --APRKS-/-----R--KSVV---A-E-------VTD--P--TAA--T--AP-----S-------EGT--Y-----G--

$5-\mathrm{A}$

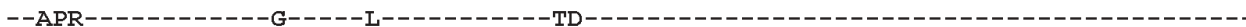

SENV-F HIDMFGTYYDRKPTSSDWGN

SAa-38 -VN---E-P-----KE--QTEYETCRAFDRPPRTLLTDPPFY PWMPKOPPTYRVSFKLGFO

5-A -V----N-------A---QTEYECCRAFDRPPRSNLKDSPFY PWMPKQSQ/FRVTFKLGF

Fig. 3: comparison by alignment of the putative proteins of isolates SENV-F, SAa-38, and 5-A. Only the C-terminal moieties of ORF3 and ORF4 products are represented since their N-terminal parts are identical to ORF2 protein. Dashes represent the same nucleotides as in the SENV-F isolate. Slashes indicate deletions. The first amino acid residue $(\mathrm{H})$ of the C-terminal part of ORF4 protein substitutes the last amino acid (Q) of ORF2 product. This does not occur for ORF3 and explains the slight discrepancy between the numberings of ORF3 and ORF4. 
Devalle S, Niel C 2004. Distribution of TT virus genomic groups 1 to 5 in Brazilian blood donors, HBV carriers, and HIV-1infected patients. J Med Virol 72: 166-173.

Fiordalisi G, Bonelli M, Olivero P, Primi D, Vaglini L, Mattioli S, Bonelli F, Dal Corso A, Mantero GL, Sottini A 2000. Identification of SENV genotypes. International patent number WO 0028039 (international application published under the patent cooperation treaty). Internet address: http:/ /ep.espacenet.com/

Hijikata M, Takahashi K, Mishiro S 1999. Complete circular DNA genome of a TT virus variant (isolate name SANBAN) and 44 partial ORF2 sequences implicating a great degree of diversity beyond genotypes. Virology 260: 17-22.

Kamahora T, Hino S, Miyata H 2000. Three spliced mRNAs of TT virus transcribed from a plasmid containing the entire genome in COS1 cells. J Virol 74: 9980-9986.

Kao JH, Chen W, Chen PJ, Lai MY, Chen DS 2002. Prevalence and implication of a newly identified infectious agent (SEN virus) in Taiwan. J Infect Dis 185: 389-392.

Kojima H, Kaita KD, Zhang M, Giulivi A, Minuk GY 2003. Genomic analysis of a recently identified virus (SEN virus) and genotypes $\mathrm{D}$ and $\mathrm{H}$ by polymerase chain reaction. $\mathrm{An}$ tiviral Res 60: 27-33.

Maggi F, Pifferi M, Fornai C, Andreoli E, Tempestini E, Vatteroni M, Presciuttini S, Marchi S, Pietrobelli A, Boner A, Pistello M, Bendinelli M 2003. TT virus in the nasal secretions of children with acute respiratory diseases: Relations to viremia and disease severity. J Virol 77: 24182425.

Mikuni M, Moriyama M, Tanaka N, Abe K, Arakawa Y 2002. SEN virus infection does not affect the progression of nonA to -E liver disease. J Med Virol 67: 624-629.

Mushahwar I 2000. Recently discovered blood-borne viruses: Are they hepatitis viruses or merely endosymbionts? J Med Virol 62: 399-404.

Niel C, de Oliveira JM, Ross RS, Gomes SA, Roggendorf M, Viazov S 1999. High prevalence of TT virus infection in Brazilian blood donors. J Med Virol 57: 259-263.

Nishizawa T, Okamoto H, Konishi K, Yoshizawa H, Miyakawa Y, Mayumi M 1997. A novel DNA virus (TTV) associated with elevated transaminase levels in posttransfusion hepatitis of unknown etiology. Biochem Biophys Res Commun 241: 92-97.

Okamoto H, Nishizawa T, Kato N, Ukita M, Ikeda H, Iizuka H, Miyakawa Y, Mayumi M 1998. Molecular cloning and characterization of a novel DNA virus (TTV) associated with posttransfusion hepatitis of unknown etiology. Hepatol Res 10: 1-16.

Okamoto H, Nishizawa T, Ukita M, Takahashi M, Fukuda M, Iizuka H, Miyakawa Y, Mayumi M 1999. The entire nucleotide sequence of a TT virus isolate from the United States (TUS01): Comparison with reported isolates and phylogenetic analysis. Virology 259: 437-448.

Okamoto H, Nishizawa T, Tawara A, Takahashi M, Kishimoto J, Sai T, Sugai Y 2000. TT virus mRNAs detected in the bone marrow cells from an infected individual. Biochem Biophys Res Commun 279: 700-707.

Okamoto H, Mayumi M 2001. TT virus: virological and ge- nomic characteristics and disease associations. $J$ Gastroenterol 36: 519-529.

Peng YH, Nishizawa T, Takahashi M, Ishikawa T, Yoshikawa A, Okamoto H 2002. Analysis of the complete genomes of thirteen TT virus variants classifiable into the fourth and fifth genetic groups, isolated from viremic infants. Arch Virol 147: 21-41.

Pirovano S, Bellinzoni M, Ballerini C, Cariani E, Duse M, Albertini A, Imberti L 2002a. Transmission of SEN virus from mothers to their babies. J Med Virol 66: 421-427.

Pirovano S, Bellinzoni M, Matteelli A, Ballerini C, Albertini A, Imberti L 2002b. High prevalence of a variant of SENV in intravenous drug user HIV-infected patients. J Med Virol 68: $18-23$.

Prescott LE, Simmonds P 1998. Global distribution of transfusion-transmitted virus. New England J Med 339: 776-777.

Schröter M, Laufs R, Zollner B, Knodler B, Schafer P, Sterneck M, Fischer L, Feucht HH 2002. Prevalence of SENV-H viraemia among healthy subjects and individuals at risk for parenterally transmitted diseases in Germany. $J$ Viral Hepatol 9: 455-459.

Schröter M, Laufs R, Zollner B, Knodler B, Schafer P, Feucht HH 2003. A novel DNA virus (SEN) among patients on maintenance hemodialysis: prevalence and clinical importance. J Clin Virol 27: 69-73.

Sherman KE, Rouster SD, Feinberg J 2001. Prevalence and genotypic variability of TTV in HIV-infected patients. Dig Dis Sci 46: 2401-2407.

Shibata M, Wang RYH, Yoshiba M, Shih JWK, Alter HJ, Mitamura K 2001. The presence of a newly identified infectious agent (SEN virus) in patients with liver disease and in blood donors in Japan. J Infect Dis 184: 400-404.

Shibayama T, Masuda G, Ajisawa A, Takahashi M, Nishizawa T, Tsuda F, Okamoto H 2001. Inverse relationship between the titre of TT virus DNA and the CD4 cell count in patients infected with HIV. AIDS 15: 563-570.

Takahashi K, Hoshino H, Ohta Y, Yoshida N, Mishiro S 1998. Very high prevalence of TT virus (TTV) infection in general population of Japan revealed by a new set of PCR primers. Hepatol Res 12: 233-239.

Tanaka Y, Primi D, Wang RY, Umemura T, Yeo AE, Mizokami M, Alter HJ, Shih JW 2001. Genomic and molecular evolutionary analysis of a newly identified infectious agent (SEN virus) and its relationship to the TT virus family. $J$ Infect Dis 183: 359-367.

Touinssi M, Gallian P, Biagini P, Attoui H, Vialettes B, Berland Y, Tamalet C, Dhiver C, Ravaux I, De Micco P, De Lamballerie X 2001. TT virus infection: prevalence of elevated viraemia and arguments for the immune control of viral load. J Clin Virol 21: 135-141.

Umemura T, Yeo AE, Sottini A, Moratto D, Tanaka Y, Wang RY, Shih JW, Donahue P, Primi D, Alter HJ 2001. SEN virus infection and its relationship to transfusion-associated hepatitis. Hepatology 33: 1303-1311.

Yoshida H, Kato N, Shiratori Y, Shao R, Wang Y, Shiina S, Omata M 2002. Weak association between SEN virus viremia and liver disease. J Clin Microbiol 40: 3140-3145. 